\title{
Determinants of physicians' medication prescribing behaviour in primary care in Riyadh city, Saudi Arabia
}

M.A. Magzoub, ${ }^{7}$ Y. Neyaz, ${ }^{2}$ T. Khoja, ${ }^{3}$ N.A. Qureshi, ${ }^{4}$ A. Haycox ${ }^{5}$ and T. Walley 6

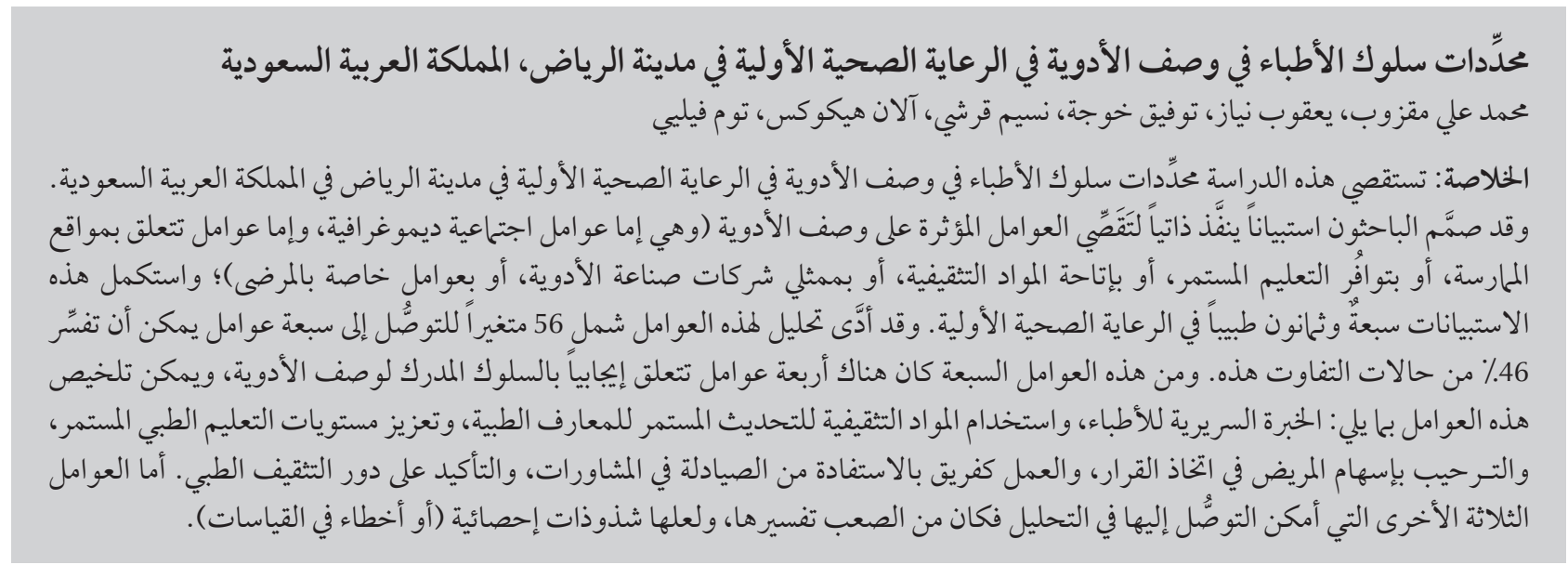

ABSTRACT This study in Saudi Arabia explored the determinants of physicians' prescribing behaviour in primary care in Riyadh city. A self-administered questionnaire designed to explore factors influencing prescribing (sociodemographic factors; practice setting; continuing education; access to educational materials; pharmaceutical company representatives; and patient factors) was completed by 87 PHC physicians. A factor analysis of 56 variables extracted 7 factors that explained $46 \%$ of the variance. Of these, 4 components positively related to perceived good prescribing behaviour could be summarized as: clinical experience of physicians; use of educational materials for continuous updating of medical knowledge; enhanced levels of continuing medical education and willingness to involve patients in decision-making; and working as a team using pharmacists for consultation and emphasizing the role of medical education. The other 3 factors derived from the analysis were less easy to interpret and may have been statistical anomalies (or measurement errors).

\section{Mode de prescription de médicaments en soins de santé primaires à Riyad (Arabie saoudite).}

RÉSUMÉ Le comportement prescripteur des médecins est étroitement lié à la sécurité des patients et ce domaine est peu étudié en Arabie saoudite. L'objectif de la présente étude était d'analyser le mode de prescription des médecins et d'évaluer la pertinence des données rédigées dans le secteur des soins de santé primaires à Riyad. Toutes les prescriptions de médicaments de cinq centres de santé publics $(n=1182)$ et de cinq centres de santé privés $(n=1200)$ ont été collectées par échantillonnage aléatoire simple au cours d'une journée de travail. Les antibiotiques étaient les médicaments les plus fréquemment prescrits dans les deux secteurs. Le nombre moyen de médicaments par prescription était de 2,08 dans le secteur public et de 2,36 dans le secteur privé. Les informations et les instructions notées sur les prescriptions variaient considérablement selon le type de centre de santé - privé ou public. Le même constat s'appliquait au mode de prescription de médicaments. Les médecins de soins de santé primaires en Arabie saoudite ont besoin d'une formation continue pour améliorer leurs pratiques de prescription. 


\section{Introduction}

An ever-increasing rise in the development of new drugs appears to coincide with an increasing incidence of medication errors [1]. The reasons for the increase in prescribing have been described before: ageing populations in developed countries with higher rates of morbidity, extension of the range of available medicines to treat previously untreatable conditions, an increase in the practice of preventive prescribing and the medicalization of non-medical problems in a consumer society $[2,3]$.

Health authorities throughout the world aim to optimize the quality of prescribing within the limitations imposed by their health care budgets. The processes by which they attempt to achieve this have been fully described in the literature reviews accompanying this paper [4-6]. Policies to achieve cost-effective prescribing need not compromise the quality of prescribing. Reasonable negotiations with the patient, meaningful consultation with physicians working in hospitals and PHC, proper scrutiny of pharmaceutical information or other sources of pharmacological data, scientifically conducted post-marketing drug trials and cognitive decision-making are all helpful to a physician in prescribing correctly in all health care systems including PHC [3].

In contrast to the extensive literature from industrialized countries on the determinants of rational drug prescribing behaviour [7], there is limited literature from Gulf countries addressing this issue. This study in Saudi Arabia used factor analysis to explore the determinants of primary health care (PHC) physicians' prescribing behaviour in the public and private health care sectors in Riyadh city. Given the wide range of determinants recognized in the literature and the difficulties of addressing this broad spectrum of issues in a research naive setting, the study concentrated on the influence of practice settings and access to educational materials and training programmes on self-declared prescribing behaviour.

\section{Methods}

The influences on self-reported prescribing behaviour of a sample of physicians were analysed using data from an anonymous questionnaire.

\section{Sample and setting}

The survey was done on a convenience sample of all the physicians working in the private and public $\mathrm{PHC}$ centres who were selected for a study of prescribing reported earlier [8]. Thus all 87 physicians (47 in the public sector and 40 in the private sector) from these 10 health centres ( 5 in the public sector and 5 in the private sector) were included. There were no refusals to participate. The sample was stratified to ensure that the full range of PHC practices was covered in both the public and private sectors.

\section{Data collection}

The study was conducted in 2004-5. Following an extensive review of the relevant literature on prescribing errors [9-12], a self-administered questionnaire was designed (available from the authors on request) that addressed the expected determinants of prescribing errors. There were 56 variables including sub-items connected to physicians' characteristics, methods of keeping their knowledge up-to-date, sources of prescribing guidance and methods of improving their knowledge of prescribing. Most of the questions were closed responses but 8 open-ended questions were included to provide a qualitative dimension which enabled the views of respondents to be collected in an unstructured manner.

The team designing the questionnaire was drawn from a number of sources: the medical education department of academic universities, Ministry of Health research units and the Gulf Cooperation Council of Health
Ministers, and contained a wide range of expertise. This expert group met 3 times under the chairmanship of the first author of this project to develop the questionnaire. The questionnaire was piloted on 20 physicians, 10 each from the private and public health sectors, to identify any unclear or difficult questions and to ensure that content and length were appropriate. Although minor adjustments were made, no major changes were required.

Once finalized, the questionnaire was distributed to the 87 physicians participating in the full study. Each physician was followed up by telephone or by personal visit to maximize the response rate.

\section{Data analysis}

The data were entered in the computer using SPSS software, version 10, following data cleaning and quality testing. For parametric variables, the mean plus standard deviation with $95 \%$ confidence intervals were computed, while for nonparametric variables the median and range were computed. Principal component analysis was employed to analyse the pattern of correlations within the set of observed responses. The questions were combined to identify a smaller number of factors that accounted for most of the variance observed in the physicians' questionnaire responses and also to generate hypotheses regarding causal mechanisms underlying physicians' prescribing behaviour in PHC. Factor scores were computed which were saved as variables to undertake a logistic regression model to predict prescription quality.

\section{Results}

\section{Sociodemographic characteristics}

All of the 87 physicians approached filled in some parts of the questionnaire; however, not all responded to all of the questions. The sociodemographic 
variables of the physicians participating in the study are shown in Table 1. The responses of all PHC physicians were pooled and no attempt was made to analyse the responses from the public and private sector separately. More than $90 \%$ were in the age range $30-50$ years; males was overrepresented (62\%); only $31 \%$ had a postgraduate qualification. Over $80 \%$ of the sample were of nonSaudi origin, which is generally representative of the ethnic origin of doctors in primary care in Saudi Arabia.

\section{Training, experience and working environment}

Table 2 provides details of the training, experience and working environment of the PHC physicians participating in the study. They worked in health centres with an average number of almost 10 physicians. The mean duration of clinical experience was around 14 years; 39\% of physicians had 11-20 years clinical

\begin{tabular}{|c|c|c|}
\hline \multicolumn{3}{|c|}{$\begin{array}{l}\text { Table } 1 \text { Sociodemographic } \\
\text { characteristics of the participating } \\
\text { physicians }(n=87)\end{array}$} \\
\hline Characteristic & No. & $\%$ \\
\hline \multicolumn{3}{|l|}{ Age (years) } \\
\hline $30-35$ & 25 & 29 \\
\hline $36-40$ & 21 & 24 \\
\hline $41-45$ & 21 & 24 \\
\hline $46-50$ & 14 & 16 \\
\hline$>50$ & 6 & 7 \\
\hline \multicolumn{3}{|l|}{ Sex } \\
\hline Male & 54 & 62 \\
\hline Female & 33 & 38 \\
\hline \multicolumn{3}{|l|}{ Nationality } \\
\hline Saudi & 7 & 8 \\
\hline Non-Saudi & 72 & 83 \\
\hline Missing data & 8 & 9 \\
\hline \multicolumn{3}{|l|}{$\begin{array}{l}\text { Postgraduate } \\
\text { qualification }\end{array}$} \\
\hline Yes & 27 & 31 \\
\hline No & 53 & 61 \\
\hline Missing data & 8 & 9 \\
\hline \multicolumn{3}{|l|}{ Specialization } \\
\hline Yes & 25 & 29 \\
\hline No & 59 & 68 \\
\hline Missing data & 3 & 3 \\
\hline
\end{tabular}

\begin{tabular}{|c|c|c|c|}
\hline Variable & Min. & Max. & Mean (SD) \\
\hline Clinical experience (years) $(n=84)$ & 3 & 36 & $14.1(7.7)$ \\
\hline $\begin{array}{l}\text { Experience at this health centre (years) } \\
\qquad(n=83)\end{array}$ & 0 & 19 & $5.7(4.4)$ \\
\hline No. of physicians at health centre $(n=82)$ & 3 & 54 & $9.5(6.7)$ \\
\hline $\begin{array}{l}\text { No. of patients seen by clinic: morning } \\
\text { shift }(n=84)\end{array}$ & 0 & 900 & $69.1(111.7)$ \\
\hline $\begin{array}{l}\text { No. of patients seen by clinic: evening } \\
\text { shift }(n=84)\end{array}$ & 0 & 355 & $82.6(88.4)$ \\
\hline $\begin{array}{l}\text { Distance of postgraduate centre from } \\
\text { health centre (miles) }(n=65)\end{array}$ & 1 & 50 & $8.6(8.2)$ \\
\hline $\begin{array}{l}\text { No. of scientific meetings at health } \\
\text { centre }(n=35)\end{array}$ & 1 & 4 & $2.5(1.3)$ \\
\hline $\begin{array}{l}\text { Training time for drug prescribing } \\
\text { (hours) }(n=13)\end{array}$ & 1 & 100 & $12.4(27.0)$ \\
\hline $\begin{array}{l}\text { No. of visits from drug company } \\
\text { representatives }(n=53)\end{array}$ & 0 & 36 & $8.0(7.9)$ \\
\hline Length of training (hours) $(n=22)$ & 1 & 11 & $1.5(2.1)$ \\
\hline Length of training (days) $(n=4)$ & 1 & 3 & $1.8(1.0)$ \\
\hline
\end{tabular}

$n=$ number of respondents; $S D=$ standard deviation .

experience and 59\% had worked for less than 5 years at the present PHC centre.

Only $52 \%$ of physicians reported using an appointment system. With regard to further education, only about $14 \%$ of physicians had diplomas in disciplines such as paediatric medicine, dermatology and ophthalmology; another 10\% had a Masters qualification.

\section{Training in drug prescribing}

Approximately two-thirds of physicians (65\%) had received no training in drug prescribing at medical school. Of those who had received training, 65\% declared that their undergraduate training in pharmacology had provided adequate education. However, a majority of PHC physicians (83\%) felt that medical undergraduates should receive additional courses in pharmacology to support their drug prescribing in primary care.

\section{Methods of updating medical knowledge}

The methods by which the sample of clinicians updated their medical knowledge are summarized in Table 3 . The most preferred method was attending lectures or presentations, $25 \%$ of PHC physicians, followed by private reading and study (20\%) and attending scientific and educational meetings (18\%); studying for a postgraduate degree was the least preferred method.

\section{Prescribing guidance}

Table 4 summarizes the sources of prescribing guidance utilized by clinicians. The great majority of physicians claimed to consult some form of drug formulary for prescribing. The most frequently used source of prescribing guidance was the Middle East Medical Index (77\% of physicians). Only about 34\% had ever consulted a pharmacist before prescribing a drug (data not shown).

\section{Knowledge of pharmacology}

Perhaps surprisingly, $18 \%$ of respondents expressed the view that pharmacology had limited importance for PHC physicians. When asked to identify the areas where prescribing problems were likely to arise, their responses were as follows: limited knowledge of pharmacology (54\%), limited skills in prescribing $(23 \%)$ and limited time to optimize prescribing (17\%).

Although 97\% of PHC physicians observed that a sound knowledge of pharmacology was required for good 


\begin{tabular}{|c|c|c|c|c|c|c|c|c|c|c|}
\hline \multirow[t]{2}{*}{ Method } & \multicolumn{2}{|c|}{$\begin{array}{c}\text { 1st } \\
\text { preference }\end{array}$} & \multicolumn{2}{|c|}{$\begin{array}{l}\text { 2nd } \\
\text { preference }\end{array}$} & \multicolumn{2}{|c|}{$\begin{array}{c}\text { 3rd } \\
\text { preference }\end{array}$} & \multicolumn{2}{|c|}{$\begin{array}{c}\text { 4th } \\
\text { preference }\end{array}$} & \multicolumn{2}{|c|}{$\begin{array}{c}\text { 5th } \\
\text { preference }\end{array}$} \\
\hline & No. & $\%$ & No. & $\%$ & No. & $\%$ & No. & $\%$ & No. & $\%$ \\
\hline Attending lectures/presentations & 22 & 25 & 28 & 32 & 59 & 68 & 9 & 10 & 16 & 18 \\
\hline Private reading and study & 17 & 20 & 13 & 15 & 11 & 13 & 4 & 5 & 1 & 1 \\
\hline Attending morning meetings & 16 & 18 & 16 & 18 & 12 & 14 & 2 & 2 & 1 & 1 \\
\hline Working on a personal project & 3 & 3 & 4 & 5 & 3 & 3 & 22 & 25 & 9 & 10 \\
\hline Study for postgraduate degree & 1 & 1 & 1 & 1 & 1 & 1 & 9 & 10 & 14 & 16 \\
\hline Missing data & 28 & 32 & 25 & 29 & 1 & 1 & 41 & 47 & 46 & 53 \\
\hline
\end{tabular}

\begin{tabular}{|c|c|c|c|c|c|c|}
\hline \multirow[t]{2}{*}{ Source } & \multicolumn{2}{|c|}{ Yes } & \multicolumn{2}{|c|}{ No } & \multicolumn{2}{|c|}{ Missing data } \\
\hline & No. & $\%$ & No. & $\%$ & No. & $\%$ \\
\hline Middle East Medical Index & 67 & 77 & 10 & 12 & 10 & 12 \\
\hline Saudi national drug formulary & 57 & 66 & 17 & 20 & 13 & 15 \\
\hline British National Formulary & 34 & 39 & 39 & 45 & 14 & 16 \\
\hline Pharmaceutical books & 32 & 37 & 32 & 37 & 23 & 26 \\
\hline Health centre drug formulary & 29 & 33 & 31 & 36 & 27 & 31 \\
\hline Regional drug formulary & 13 & 15 & 43 & 49 & 31 & 36 \\
\hline
\end{tabular}

prescribing, only $16 \%$ reported having received any form of continuing medical education or on-the-job training in drug prescribing. In cases where such education and training had been provided, it was usually provided by the Ministry of Health.

\section{Enhancing professional knowledge}

Of the PHC physicians $84 \%$ reported that obtaining the relevant medical literature was easy and that this represented their predominant means of enhancing their professional knowledge and prescribing ability.

Table 5 summarizes the information sources that were felt to be of the greatest value in improving their knowledge. The major influences on knowledge of prescribing were lectures (47\%) and study groups at the health centre (18\%).

\section{Medical representatives}

Only $36 \%$ of physicians considered the visits by medical representatives to be useful and timely and 60\% reported attendance at meetings organized by pharmaceutical companies during the past year, with the major motivation for attendance being to learn more about drug prescribing. Many physicians (61\%) reported that they found the visits by drug representatives to be a positive influence, with $25 \%$ stating that such visits had changed their attitudes and $22 \%$ reporting a change in prescribing behaviour as a result.

\begin{tabular}{lcc}
\hline Table 5 Principle method of improving knowledge about prescribing reported by \\
physicians working in primary health care centres in Riyadh city $(\boldsymbol{n}=\mathbf{8 7})$
\end{tabular}

\section{Regulations and guidelines}

Of the $83 \%$ of PHC physicians who reported having regulations or guidelines for the management of chronic/ acute diseases at the health centre, only $71 \%$ followed such guidelines, with the remainder reporting no effect of regulations or guidelines on their drug prescribing. Three-quarters of $\mathrm{PHC}$ physicians reported having access to a quality assurance manual at the health 
centre, although only $66 \%$ reported actually using the manual to support their prescribing.

\section{Patients}

Less than half the physicians (49\%) took specific action to explore the benefits and harms of drug use by following up the outcome of individual patients. Notably, only $40 \%$ of physicians specifically discussed the issue of prescribing with their visiting supervisors.

A majority of PHC physicians (81\%) stated that they offered their patients education and counselling about the prescribed medications, which they believed to be effective in $63 \%$ of cases; however, overhalf reported that patients had no role in determining their prescribing behaviour.

\section{Principal component analysis of prescribing in Saudi Arabia}

Factor analysis was used to ascertain patterns in the responses of primary care physicians to the range of issues covered in the questionnaire. Principal component analysis of 56 variables revealed that $76 \%$ of variance was explained by 18 components that had eigen values $\geq 1$.0. These 18 principal components were considered for further analysis. All components with an eigen value of $<1.0$ were omitted from the analysis because their contribution in determining the pattern of responses was not significant. Further analysis (rotation method varimax with Kaiser normalization) extracted 7 components with eigen values $\geq 2.0$ and these 7 factors explained $46 \%$ of the variance. A component transformation matrix was used and factor loadings which appeared to represent significant determinants of physicians' drug prescribing were obtained (both positively and negatively oriented questions were used in the questionnaire to minimize an automatic response bias by the respondents).

The determinants with heavy factor loadings (i.e. $\geq+0.5$ or -0.5 ) and the 7 components positively related to self- reported good prescribing behaviour are shown in Table 6. Four of the components could be interpreted as follows: physician's clinical experience (factor 3 ); use of educational materials for continuous updating medical knowledge (factor 4); enhanced level of continuing medical education and willingness to involve patients in decision-making (factor 5); and working as a team using pharmacists for consultation and emphasizing the role of medical education for patients regarding drug use (factor 6). The other 3 factors derived from the analysis were less easy to interpret. Factor 2 appeared to combine items that exhibited scepticism about the value of meetings in altering prescribing behaviour (with the notable exception of meetings organized by medical representatives). Factor 1 appeared to combine items about the positive impact of the size and organization of the health centre on improving prescribing (with the notable exception of the attitude of physicians towards pharmacology). Finally, factor 7 grouped the 2 seemingly unrelated issues of physician nationality and attending distance learning courses on the quality of prescribing.

\section{Discussion}

The predictors of drug prescribing in this study in PHC in Riyadh, Saudi Arabia, were distributed among 7 components, 4 of which could be summarized as: clinical experience of physicians; use of educational materials for continuous updating medical knowledge; enhanced levels of continuing medical education and willingness to involve patients in decision-making; and working as a team using pharmacists for consultation and emphasizing the role of medical education. The other 3 factors derived from the analysis were less easy to interpret and may have been statistical anomalies.

In our study the knowledge of physicians, acquired during undergraduate and on-the-job training, and their active attempts to update their knowledge all appeared to be positively related to their views of the prescribing behaviour. These appear to reflect the range of issues identified in the literature as affecting prescribing behaviour. Educational approaches such as access to published drug information, coupled with feedback on prescribing have been shown by other studies to influence the prescribing habits of physicians [13-19]. Furthermore, the knowledge base of PHC physicians also determines their prescribing behaviour [20].

Medical representatives' visits were not believed by physicians to affect their prescribing behaviour (factor loading $-0.5)$. Again, this perception mirrors those of other studies in which clinicians themselves denied the impact of such visits on their pattern of prescribing [21]. Such perceptions, however, are difficult to reconcile with the significant resources invested by pharmaceutical companies in supporting such visits. Again, this could be an area in which physicians' perceptions and clinical reality are at odds with each other.

In our research, education of the patient regarding drug use and utilization and their active participation in the decision of drug prescribing were considered by physicians to be influential on their prescribing pattern (factor loading $>+0.5$ ). Evidently, the active participation of the patient both in education and decision-making of drug prescribing should be encouraged by health authorities at all levels of health care delivery [22,23].

A number of other factors also improved the quality of prescribing (factor loadings $>+0.5$ ). These included: consultation with a pharmacist before prescribing, access to visiting supervisors to discuss rational drug prescribing, the presence of assistant pharmacists in the pharmacy; accurate completion of information in patient clinical management forms; and the number of patients seen in the PHC clinic. 


\begin{tabular}{|c|c|}
\hline \multicolumn{2}{|c|}{$\begin{array}{l}\text { Table } 6 \text { Determinants and factor loadings }(0.5 /-0.5) \text { of self-reported prescribing } \\
\text { behaviour of physicians working in primary health care centres (PHC) in Riyadh } \\
\text { city }(n=87)\end{array}$} \\
\hline Factor /determinant & Loading \\
\hline \multicolumn{2}{|l|}{ Factor 1} \\
\hline No. of patients seen (last 6 months, morning shift) & 0.72 \\
\hline No. of patients seen (last 6 months, evening shift) & 0.73 \\
\hline Assistant pharmacist at PHC centre & 0.61 \\
\hline Drug formulary at PHC & 0.63 \\
\hline Training in prescribing during medical school & 0.66 \\
\hline Adequacy of undergraduate training in drug prescribing & 0.58 \\
\hline Patient education and effective evaluation & 0.67 \\
\hline Using prescribing guidelines at $\mathrm{PHC}$ centre & 0.75 \\
\hline Physician attitude of towards pharmacology & -0.55 \\
\hline Quality assurance manual present at PHC centre & 0.71 \\
\hline Use of quality assurance manual at PHC centre & 0.62 \\
\hline \multicolumn{2}{|l|}{ Factor 2} \\
\hline Meetings attendance and prescribing ${ }^{a}$ & 0.55 \\
\hline Meetings change my attitude & -0.80 \\
\hline Meetings change my behaviour & -0.80 \\
\hline Meetings change my past experience & -0.70 \\
\hline Meetings change my knowledge & -0.70 \\
\hline \multicolumn{2}{|l|}{ Factor 3} \\
\hline Physician age & 0.80 \\
\hline Physician total years of experience & 0.79 \\
\hline Physician years of experience in this health centre & 0.73 \\
\hline \multicolumn{2}{|l|}{ Factor 4} \\
\hline Use of Saudi national drug formulary & 0.67 \\
\hline Use of pharmaceutical books & 0.58 \\
\hline \multicolumn{2}{|l|}{ Factor 5} \\
\hline Frequency of scientific meetings in PHC centre & 0.57 \\
\hline Frequency of scientific meeting attended & 0.57 \\
\hline On-job training in drug prescribing & 0.62 \\
\hline Patients influence my prescribing decisions & 0.56 \\
\hline \multicolumn{2}{|l|}{ Factor 6} \\
\hline $\begin{array}{l}\text { Complete of all information in clinical management } \\
\text { form }\end{array}$ & 0.51 \\
\hline Consultation with the pharmacist before prescribing & 0.54 \\
\hline $\begin{array}{l}\text { Education of the patient regarding drug use and } \\
\text { utilization }\end{array}$ & 0.65 \\
\hline \multicolumn{2}{|l|}{ Factor 7} \\
\hline Physician nationality & -0.58 \\
\hline Distance learning programmes on prescribing & 0.46 \\
\hline
\end{tabular}

${ }^{a}$ Visits and meetings organized by drug company representatives.

These findings emphasize the importance of providing physicians in Saudi Arabia with ongoing training in drug prescribing, together with access to relevant educational materials. Prescribing determinants such as the age of the physicians, length of clinical experience, effective evaluation skills, appropriate diagnosis and treatment and patient education all appeared to be powerful predictors of physicians' prescribing. The development of a teamwork approach between physician, pharmacist and patient seems to be a key element in improving prescribing behaviour.

We can identify some areas of improvement for future studies. The factor analysis undertaken in this analysis explained only $46 \%$ of the variance. Further research, perhaps in the form of qualitative research with indepth discussions with physicians might help to further extend our knowledge of optimal prescribing behaviour in $\mathrm{PHC}$ in Saudi Arabia. Further studies are warranted to explore the determinants of drug prescribing not considered in this analysis.

It is important to recognize that this study had some of weaknesses. Although the questionnaire for the study was established by rigorous methodology, the areas covered were identified by the authors from the literature and in discussion with colleagues and were not derived from formal qualitative research, e.g. discussions with $\mathrm{PHC}$ physicians and thematic analysis until saturation of topics was achieved. Furthermore, the questionnaire reflects PHC physicians' self-reported views and may therefore have been biased if they reported what they considered acceptable to say rather than what they actually thought and still less what they actually do.

Again, more observational research and direct challenging of doctors about their management of specific cases would have been enlightening but was beyond the scope of this study. There was also some evidence of inaccuracies in completion of the questionnaires: as all the practices were located in Riyadh, it is difficult to see how one of the practices perceived itself as being 50 miles from a postgraduate centre; equally, it is unlikely that 1 clinic was able to see 900 patients in a morning shift.

In this study we identified a range of possible determinants of self-perceived 
drug prescribing by physicians working in private and public health sectors. In addition, it has acknowledged its weaknesses and indicated a wide range of possible future areas for further research. As previously emphasized, the aim was not to obtain definitive results, but rather to open up this area of research and to provide guidance to other researchers who may wish to develop these analyses in Saudi Arabia and beyond.

\section{References}

1. Barber ND, Dean BS. The incidence of medication errors and ways to reduce them. Clinical Risk, 1998, 4:103-106.

2. Fernandez-Liz et al. Identifying how age and gender influence prescription drug use in a primary health care environment in Catalonia, Spain. British Journal of Clinical Pharmacology, 2008, 407-417.

3. Qureshi NA et al .Psychotropic drug prescriptions in primary care and general hospitals in Saudi Arabia. Saudi Pharmaceutical Journal, 2001, 9:193-200.

4. Neyaz $\mathrm{Y}$ et al. Physicians' medication prescribing in primary care in Riyadh city, Saudi Arabia. Literature review, part 1: variations in drug prescribing. Eastern Mediterranean Health Journal, 2011, 17(2):126 -131.

5. Khoja T et al. Physicians' medication prescribing in primary care in Riyadh city, Saudi Arabia. Literature review, part 2: rational prescribing. Eastern Mediterranean Health Journal, 2011, 17(2)132-139.

6. Qureshi NA. Physicians' medication prescribing in primary care in Riyadh city, Saudi Arabia. Literature review, part 3: prescribing errors. Eastern Mediterranean Health Journal, 2011, 17(2)140-148

7. Bradley CP. Decision making and prescribing patterns-a literature review. Family Practice, 1991, 8:276-287.

8. Neyaz $\mathrm{Y}$ et al. Medication prescribing pattern in primary care in Riyadh city, Saudi Arabia. Eastern Mediterranean Health Journal, 2011, 17(2):149-155.

9. Britten $\mathrm{N}$ et al. Developing a measure for the appropriateness of prescribing in general practice. Quality and Safety in Health Care, 2003, 12:246-250.

10. Boynton PM. Administering, analysing, and reporting your questionnaire. British Medical Journal, 2004, 328:1372-1375.

11. Boynton PM, Greenhalgh T. Selecting, designing, and developing your questionnaire. British Medical Journal, 2004, 328:1312-1315.

12. Boynton PM, Wood GW, Greenhalgh T. Reaching beyond the white middle classes. British Medical Journal, 2004, 328:14331436
13. Belongia EA et al. Impact of statewide program to promote appropriate antimicrobial drug use. Emerging Infectious Diseases, 2005, 11:912-920.

14. Odusanya OO, Oyediran MA. The effect of an educational intervention on improving rational drug use. Nigerian Postgraduate Medical Journal, 2004, 11:126-131.

15. Maxwell S, Walley T; BPS Clinical Section Committee. Teaching safe and effective prescribing in UK medical schools: a core curriculum for tomorrow's doctors. British Journal of Clinical Pharmacology, 2003, 55:496-503.

16. Lesar T et al. Using the ISMP Medication Safety Self-Assessment to improve medication use processes. Joint Commission Journal on Quality and Safety, 2003, 29:211-226.

17. Dean $B$ et al. Causes of prescribing errors in hospital inpatients: a prospective study. Lancet, 2002, 359:1373-1378.

18. François $\mathbf{P}$ et al. Evaluation of a program to improve the prescription-writing quality in hospital. International Journal of Health Care Quality Assurance Incorporating Leadership in Health Services, 2001, 14:268-274.

19. Hogerzeil HV et al. Impact of an essential drugs programme on availability and rational use of drugs. Lancet, 1989, 1:141-142.

20. Leblebicioglu $\mathrm{H}$ et al. Physicians' antibiotic prescribing habits for upper respiratory tract infections in Turkey. Journal of Chemotherapy (Florence, Italy), 2002, 14:181-184.

21. Felimban FM. The prescribing practice of primary health care physicians in Riyadh city. Saudi Medical Journal, 1993, 14:335-338.

22. Khoja T et al. Quality of prescribing at primary care centres in Saudi Arabia. Journal of Pharmacy Technology, 1996, 12:284-288.

23. The facts about pharmaceutical marketing promotion. Washington DC, Pharmaceutical Research and Manufacturers of America, 2008 (http://www.phrma.org/files/attachments/ Marketing\%20and\%20Promotion\%20Facts_071108_FINAL. pdf, accessed 9 January 2011). 